\title{
Echocardiographic evidence of an intrapulmonary shunt in a patient with severe liver cirrhosis
}

\author{
Henrike Dobbermann ${ }^{1} \cdot$ Christoph Marquetand ${ }^{2} \oplus$. Jens U. Marquardt ${ }^{1} \cdot$ Jan-Christian Reil $^{2}$
}

Received: 19 November 2020 / Accepted: 3 February 2021 / Published online: 23 February 2021

(c) The Author(s) 2021

Keywords Echocardiography $\cdot$ Hepatopulmonary syndrome $\cdot$ Shunt $\cdot$ Contrast medium $\cdot$ Dyspnea

Sirs:

Echocardiography is the most useful screening test [1] in diagnosing intrapulmonary shunts in patients with severe liver cirrhosis and those suspected of having hepatopulmonary syndrome.

The provided image (see Fig. 1) is an anatomic M-mode representation of the left and right ventricles of a patient who suffered from gradual progressive shortness of breath in the previous weeks and cryptogenic liver cirrhosis. Exactly three heart beats after having reached the right ventricle the contrast medium, a Gelafundin ${ }^{\circledR}$ air mixture that normally cannot pass the pulmonary vasculature, opacifies the left heart chambers. The corresponding video demonstrates the influx of contrast medium through the pulmonary veins (see video 1 and Fig. 2). This finding is highly suggestive for intrapulmonary shunts. Accordingly, ASD and PFO were excluded by TOE examination 5 years before. The further echocardiographic examination revealed normal left and right ventricular function and excluded valvular heart disease. Additionally, the echo-derived pulmonary vascular resistance was rather low $($ PVR Echo $=0.1618+10.006 *$ $\mathrm{TRV}_{\max } / \mathrm{VTI}_{\mathrm{RVOT}}$ according to [2] $=0.1618+10.006 * 1.6$

Henrike Dobbermann and Christoph Marquetand contributed equally to this work.

Christoph Marquetand

christoph.marquetand@uksh.de

1 Klinik Für Innere Medizin I, Universitätsklinikum Schleswig-Holstein, Campus Lübeck, Ratzeburger Allee 160, Lübeck, Germany

2 Klinik Für Innere Medizin II, Kardiologie, Angiologie Und Internistische Intensivmedizin, Universitäres Herzzentrum Lübeck, Universitätsklinikum Schleswig-Holstein, Campus Lübeck, Ratzeburger Allee 160, Lübeck, Germany $\mathrm{m} / \mathrm{s} / 18 \mathrm{~cm}=1.05=1.05$ Wood Units) and cardiac output was slightly increased up to $6.5 \mathrm{~L} / \mathrm{min}$ while right and left ventricular flow ratio $\mathrm{Qp} / \mathrm{Qs}$ was about 1, thereby further indicating lack of intracardiac shunts. The patient showed severe hypoxemia with a $\mathrm{PO}_{2}$ of $40 \mathrm{mmHg}$ in ambient air, while dyspnea symptoms improved subjectively when the patient laid down (platipnoea). The triad of liver disease with hypoxemia caused by intrapulmonary shunts is characteristic for the hepatopulmonary syndrome. Pathophysiologically, the impaired liver function possibly favours the accumulation of vasoactive substances in the lung thereby reopening small vascular shunts [3]. Hepatopulmonary syndrome is estimated to be found in $4-47 \%$ of patients with liver disease [4]. The prognosis of these patients is rather limited with a median survival of 10 months [5]. Liver transplantation is currently the only existing therapy in this situation [6]. After diagnosis of hepatopulmonary syndrome our patient was listed for high urgency liver transplantation, but unfortunatedly died 4 weeks later. Considering the clinical implications, patients with HPS and liver disease who are suffering from dyspnea should be tested for intrapulmonary shunts to accelerate the evaluation process for liver transplantation as early as possible.. 


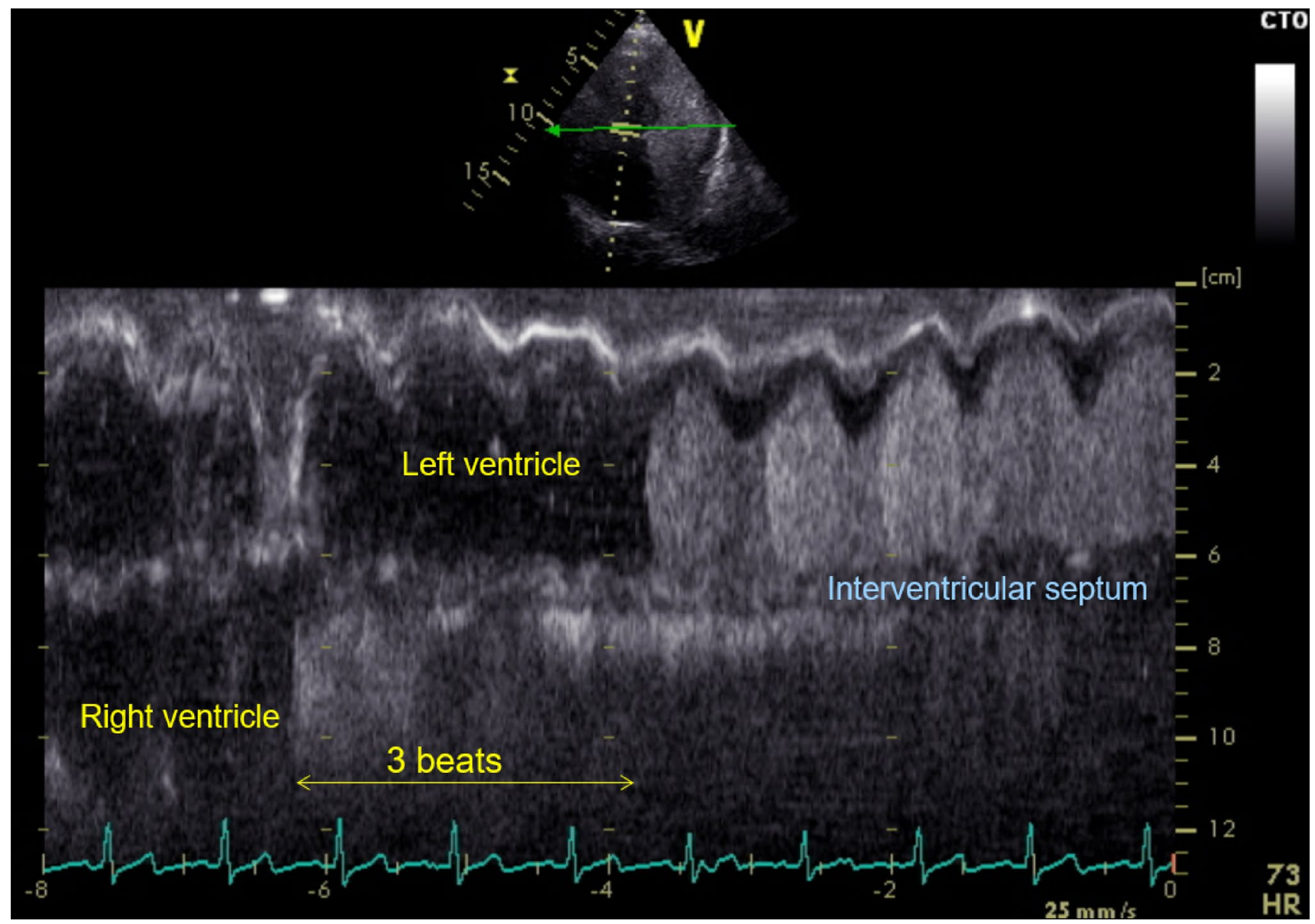

Fig. 1 Anatomical M-mode of the left and right ventricle. The left ventricle is opacificated by contrast medium (Gelafundin ${ }^{\circledR}$ air mixture) three heart cycles after the right ventricle 

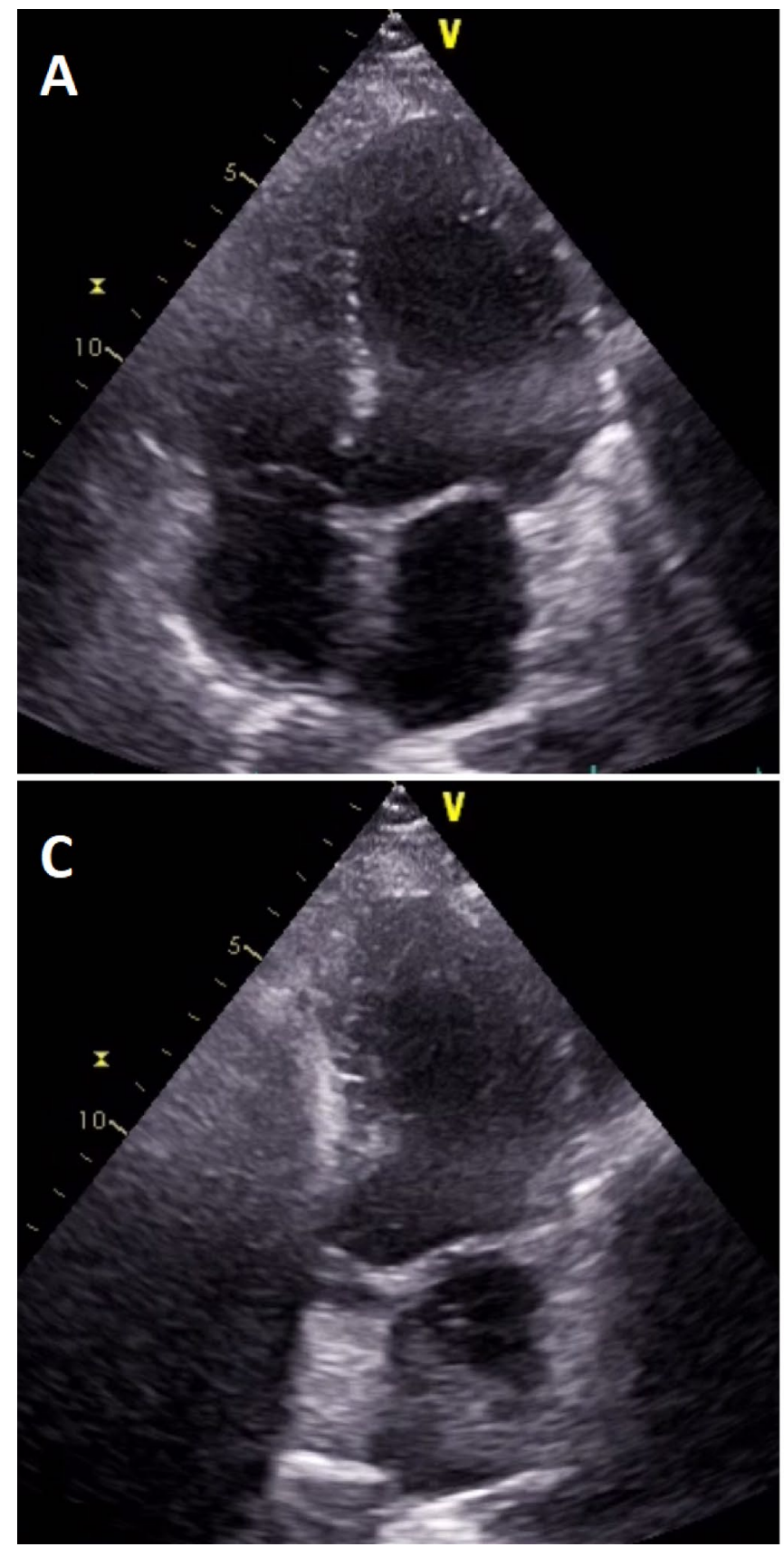

Fig. 2 Still view of video 1. Panel a shows the 4 chamber view of the heart without contrast medium. Panel $\mathbf{b}$ shows opacification of the right chambers. Panel $\mathbf{c}$ shows the contast medium shows the influx

Supplementary Information The online version contains supplementary material available at https://doi.org/10.1007/s00392-021-01817-y.

Author's contribution HD: conception of the case and writing of the manuscript. CM: conception of the case and writing of the manuscript. JM: critically reviewing the manuscript. JCR: performing the echocardiography and critically reviewing the manuscript.
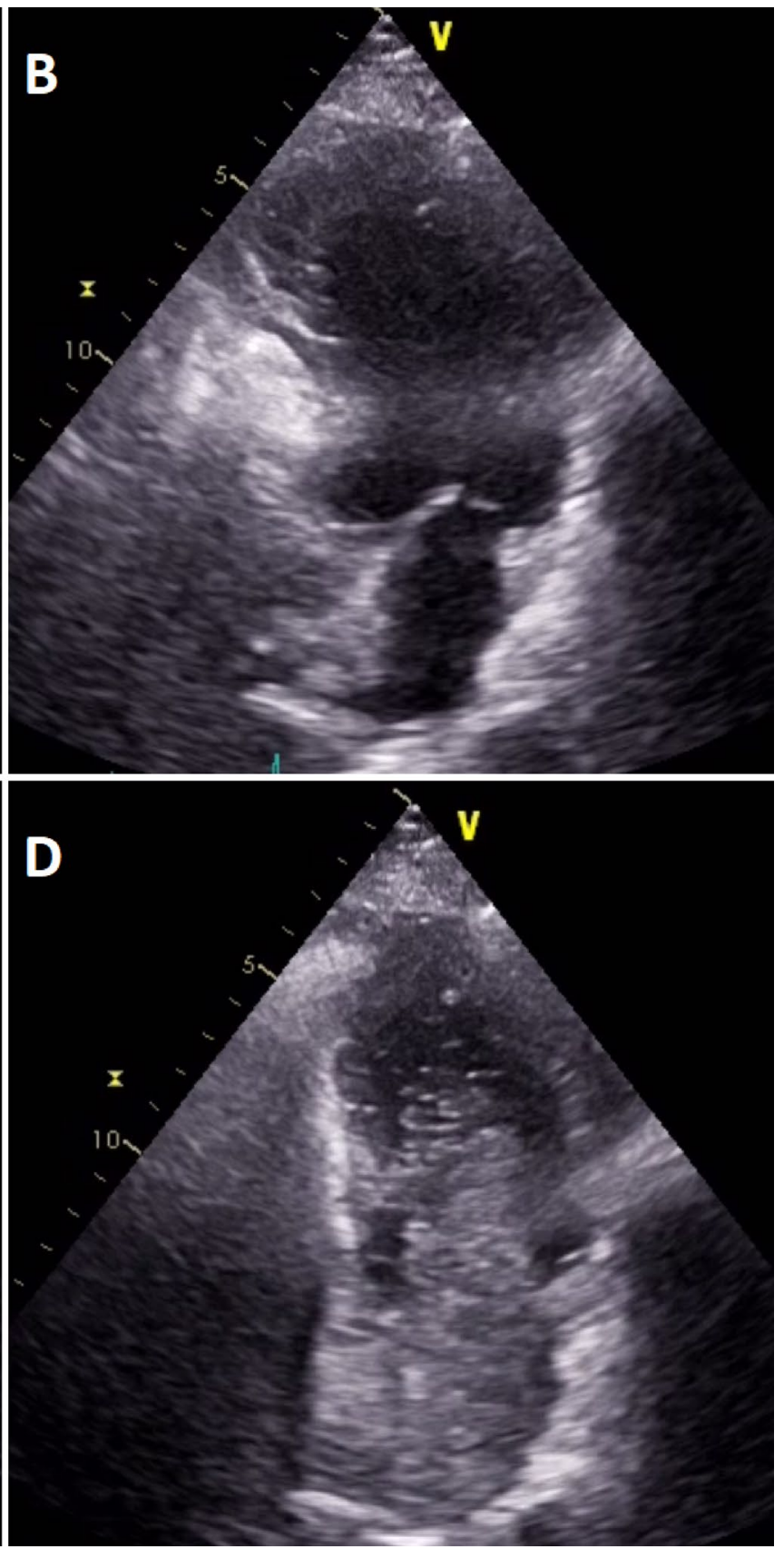

of the contrast medium through the pulmonary veins into the left atrium. Panel $\mathbf{d}$ shows the opacification of the left ventricle

Funding Open Access funding enabled and organized by Projekt DEAL.

\section{Compliance with ethical standards}

Conflict of interest All authors state that they do not have any conflicts of interest.

Consent to participate Informed consent was obtained. 
Consent for publication Informed consent was obtained.

Open Access This article is licensed under a Creative Commons Attribution 4.0 International License, which permits use, sharing, adaptation, distribution and reproduction in any medium or format, as long as you give appropriate credit to the original author(s) and the source, provide a link to the Creative Commons licence, and indicate if changes were made. The images or other third party material in this article are included in the article's Creative Commons licence, unless indicated otherwise in a credit line to the material. If material is not included in the article's Creative Commons licence and your intended use is not permitted by statutory regulation or exceeds the permitted use, you will need to obtain permission directly from the copyright holder. To view a copy of this licence, visit http://creativecommons.org/licenses/by/4.0/.

\section{References}

1. Abrams GA, Jaffe CC, Hoffer PB, Binder HJ, Fallon MB (1995) Diagnostic utility of contrast echocardiography and lung perfusion scan in patients with hepatopulmonary syndrome. Gastroenterology 109:1283-1288
2. Abbas AE, Fortuin FD, Schiller NB, Appleton CP, Moreno CA, Lester SJ (2003) A simple method for noninvasive estimation of pulmonary vascular resistance. J Am CollCardiol 41:1021-1027

3. Grace JA, Angus PW (2013) Hepatopulmonary syndrome: update on recent advances in pathophysiology, investigation, and treatment. J GastroenterolHepatol 28:213-219

4. Stoller JK, Lange PA, Westveer MK, Carey WD, Vogt D, Henderson JM (1995) Prevalence and reversibility of the hepatopulmonary syndrome after liver transplantation. The Cleveland Clinic experience. West J Med 163:133-138

5. Schenk P, Schöniger-Hekele M, Fuhrmann V, Madl C, Silberhumer G, Müller C (2003) Prognostic significance of the hepatopulmonary syndrome in patients with cirrhosis. Gastroenterology 125:1042-1052

6. EASL Clinical Practice Guidelines for the management of patients with decompensated cirrhosis. J Hepatol. 2018; 69:406-460 